\title{
Echocardiographic analysis of posterior mitral leaflet movement in mitral stenosis
}

\author{
M. F. SHIU, B. S. JENKINS, AND M. M. WEBB-PEPLOE \\ From The Cardiac Department, St Thomas' Hospital, London
}

SUMMARY Echocardiographic analysis of the movement of the posterior mitral valve leaflet in 60 patients with lone mitral stenosis, 35 patients with aortic stenosis, and 18 patients with aortic and mitral stenosis showed a spectrum of initial posterior mitral valve leaflet movement in early diastole. The classical anterior movement was seen in 36 out of 60 patients with mitral stenosis $(60 \%)$, and 8 out of 16 patients with aortic and mitral stenosis $(50 \%)$. Normal posterior movement was present in all patients with lone aortic stenosis but was also seen in 10 patients (17\%) with mitral stenosis and 6 patients $(33 \%)$ with aortic and mitral stenosis. The remaining patients with mitral stenosis or aortic stenosis and mitral stenosis showed a biphasic type of initial movement.

Patients with anterior movement had a mean calculated mitral valve area from cardiac catheterisation significantly smaller than the rest $(P<0.001)$, but neither biphasic nor posterior movement excluded severe mitral stenosis.

The distinction between patients with mitral stenosis and initial movement of the posterior mitral valve leaflet and patients with left ventricular discompliance is possible when there is sinus rhythm. Late diastolic anterior movement of the posterior mitral valve leaflet during atrial contraction is diagnostic of true mitral stenosis.

Visualisation of the posterior mitral valve leaflet is crucial to the echocardiographic diagnosis of mitral stenosis, as a decreased E-F slope and a small excursion of the anterior leaflet are seen in other conditions associated with slow left ventricular filling (Shah et al., 1969; Goodman et al., 1974; Quinones et al., 1974). In valvar aortic stenosis left ventricular filling is often slow (Stewart et al., 1968), and the E-F slope is decreased in the absence of any mitral valve disease. Unless the valve cusps are very thickened, echocardiographic diagnosis of coexisting mitral stenosis depends on abnormal movements of the posterior mitral valve leaflet.

In early diastole the posterior mitral valve leaflet may move posteriorly or anteriorly, or its movement may be biphasic (Fig. 1). Posterior movement is seen with normal valves, and also in the pseudomitral stenosis of decreased left ventricular compliance, but has also been shown in true mitral stenosis (Flaherty et al., 1975; Ticzon et al., 1975). Anterior movement is characteristic of mitral steriosis (Duchak et al., 1972; Levisman et al., 1975). Biphasic movement has been observed previously in

Received for publication 2 May 1977
Table 1 Surgical outcome of patients with isolated mitral stenosis

\begin{tabular}{lccc}
\hline $\begin{array}{l}\text { Posterior mitral valve leaflet } \\
\text { movement in early diastole }\end{array}$ & Anterior & Biphasic & Posterior \\
\hline Total & 36 & 14 & 10 \\
Mitral valve replacement & 14 & 3 & - \\
Mitral valvotomy & 18 & 7 & 5 \\
No operation & 4 & 4 & 5 \\
\hline
\end{tabular}

mitral stenosis (Popp, 1976) but its significance has not been determined.

At end-diastole the posterior mitral valve leaflet moves posteriorly with atrial contraction in the normal heart. Anterior movement of posterior mitral valve leaflet at end-diastole has not been studied with respect to its possible value in distinguishing between pseudo and true mitral stenosis.

This paper presents an analysis of the movement of the posterior mitral valve leaflet in 60 patients with proven lone mitral stenosis. The posterior mitral valve leaflet movement was also defined in 53 patients with aortic stenosis, to determine whether criteria for true mitral stenosis (in addition to aortic stenosis) could be established in this clinically important group. 


\section{Subjects and methods}

The study included 113 patients undergoing diagnostic cardiac catheterisation for mitral stenosis (60), aortic stenosis (35), or a combination of both lesions (18) in whom a satisfactory echocardiographic recording of the posterior mitral valve leaflet was obtained. No patient with more than mild valve regurgitation was included in the study.

Cardiac catheterisation included transseptal puncture using the long sheath technique (Brooksby et al., 1974) to obtain direct left atrial pressure. Simultaneous left ventricular pressure was obtained from a catheter passed retrogradely across the aortic valve. In the presence of aortic stenosis these pressures were measured by a twin-lumen catheter placed across the mitral valve. Cardiac output was measured by indocyanine green dye dilution. Mitral valve area was calculated from the Gorlin formula (Gorlin and Gorlin, 1951). Left ventricular and aortic root cineangiograms excluded significant mitral or aortic regurgitation. Echocardiograms were performed on the day before cardiac catheterisation using an Ekoline 20 ultrasonoscope with a 2.25 $\mathrm{MHz} 10 \mathrm{~cm}$ focused transducer. Recordings were made on photographic paper at speeds of 50 , 75 , or $100 \mathrm{~mm} / \mathrm{s}$. A recording was made as the ultrasound beam was swept from the mitral valve ring to the chordae to detect the presence of biphasic or posterior movement of the posterior mitral valve leaflet. Examples of the various types of posterior mitral valve leaflet movement in early and in late diastole are shown in Fig. 1 and 2. In patients with aortic stenosis the E-F slope of the anterior mitral leaflet was measured by the standard method.

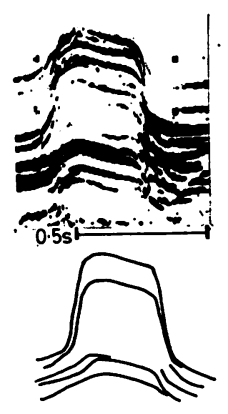

Anterior
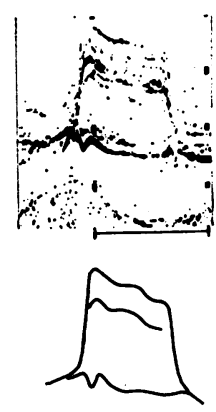

Biphasic
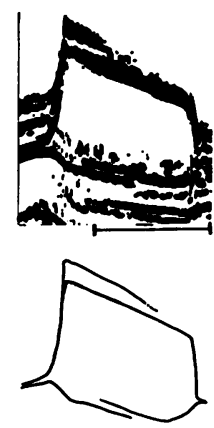

Posterior
Fig. 1 Mitral echograms from 3 patients with mitral stenosis. Anterior, biphasic, and posterior early diastolic movement of the posterior mitral valve leaflet are shown. Late diastolic movement cannot be classified because of atrial fibrillation.

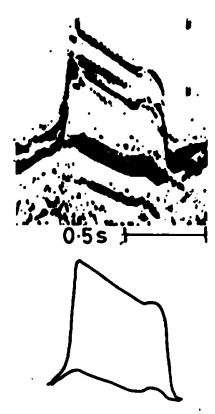

Anterior

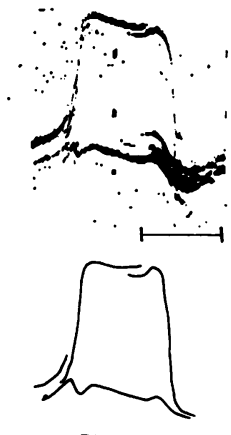

Biphasic
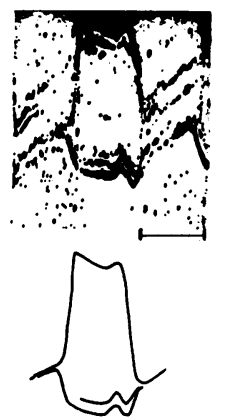

Posterior
Fig. 2 Mitral echograms from 3 patients with mitral stenosis in sinus rhythm. Three types of early diastolic movement of the posterior mitral valve leaflet are seen as in Fig. 1, but during atrial systole posterior mitral valve leaflet movement is anterior in all patients with proven mitral stenosis.

\section{Results}

Only 36 of 60 patients $(60 \%)$ with lone mitral stenosis had the characteristic anterior movement of the posterior mitral valve leaflet in early diastole. Fourteen $(23 \%)$ had biphasic and $10(17 \%)$ had normal movement (Fig. 3). Patients with either posterior or biphasic movement tended to have less severe mitral stenosis (mitral valve area $2.0 \pm 0.7$ $\mathrm{cm}^{2}$ and $1.9 \pm 0.7 \mathrm{~cm}^{2}$, respectively). Patients with

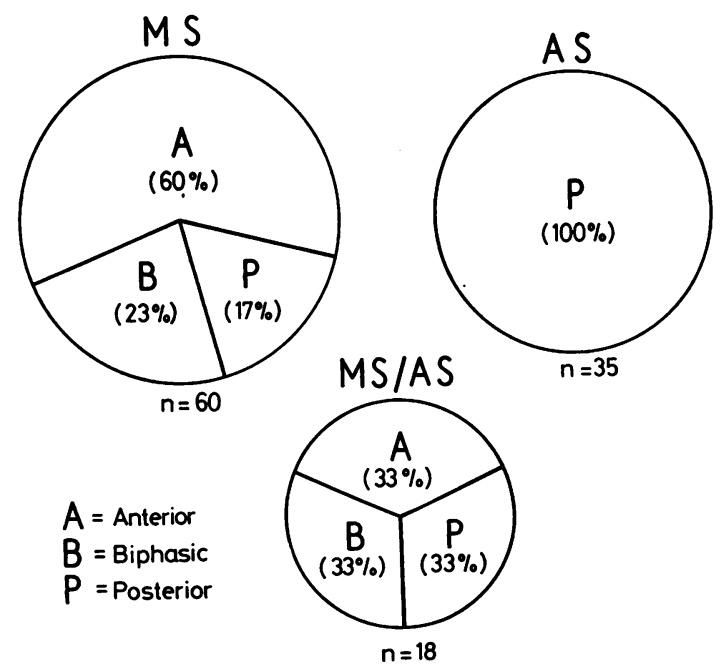

Fig. 3 Early diastolic posterior mitral valve leaflet movement in patients with mitral stenosis (MS) (60), aortic stenosis $(A S)(35)$, or $M S$ and $A S(18)$. Normal posterior movement is twice as common in combined $A S /$ $M S$ than in lone MS. 


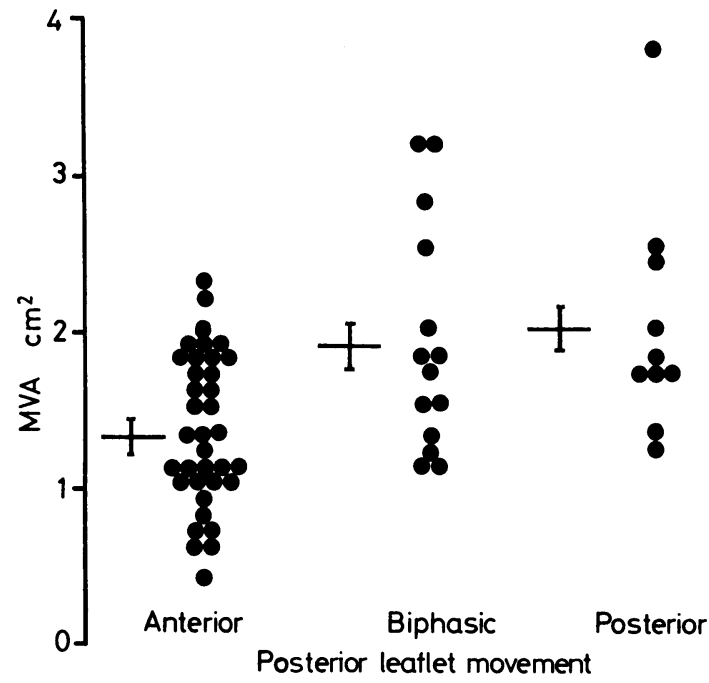

Fig. 4 Calculated Gorlin mitral valve area $(M V A)$ in 60 patients with lone mitral stenosis grouped according to early diastolic posterior mitral valve leaflet movement. Mean $M V A$ for each group is: anterior $1.3 \pm 0.5 \mathrm{~cm}^{2}$; biphasic $1.9 \pm 0.7 \mathrm{~cm}^{2}$; and posterior $2.0 \pm 0.7 \mathrm{~cm}^{2}$.

anterior posterior mitral valve leaflet movement had more severe mitral stenosis (mitral valve area $1.3 \pm$ $0.5 \mathrm{~cm}^{2}$ ) than the other two groups combined $(P<0.001)$ (Fig 4). Five of the 10 patients with posterior movement, 7 of the 14 patients with biphasic movement, but only 7 of the 56 patients with anterior movement were in sinus rhythm. Late diastolic movement of the posterior mitral valve leaflet with atrial systole was anterior in all these patients irrespective of the early diastolic movement (Fig. 2) and is thus a more reliable diagnostic sign of mitral stenosis than early diastolic movement.

All 35 patients with isolated aortic stenosis had normal posterior movement of the posterior mitral valve leaflet in early diastole; 32 were in sinus rhythm and late diastolic movement was also normal in this group. The mean E-F slope in the patients with lone aortic stenosis was $52 \mathrm{~mm} / \mathrm{s}$, the lowest value being $12 \mathrm{~mm} / \mathrm{s}$. Of the 18 patients with combined aortic and mitral stenosis, mitral stenosis was confirmed at cardiac catheterisation by simultaneous mitral valve pressure gradient in 14 and withdrawal pressure gradient in 3 . In 1 patient (case 16), mitral stenosis was not diagnosed at cardiac catheterisation or at the time of aortic valve replacement; this patient died of postoperative complications and necropsy disclosed a stenosed mitral valve (Table 2).

Of the 18 patients with aortic and mitral stenosis, 6 had the classical anterior movement of the posterior mitral valve leaflet in early diastole, 6 had biphasic initial movement, and 6 had normal posterior movements (Fig. 3). Five of the patients with posterior mitral valve leaflet movement were in sinus rhythm, and all had anterior posterior mitral valve leaflet movement with atrial systole (Fig. 5).

Table 2 Posterior mitral valve leaflet movement, Gorlic mitral valve area, and surgical outcome in patients with combined aortic and mitral stenosis

\begin{tabular}{|c|c|c|c|c|}
\hline $\begin{array}{l}\text { Case } \\
\text { No. }\end{array}$ & $\begin{array}{l}\text { Early diastolic } \\
P M V L \text { movement }\end{array}$ & $\begin{array}{l}\text { Atrial systolic } \\
P M V L \text { movement }\end{array}$ & $\begin{array}{l}\text { Gorlin mitral } \\
\text { valve area }\left(\mathrm{cm}^{2}\right)\end{array}$ & Operation \\
\hline $\begin{array}{l}1 \\
2 \\
3 \\
4 \\
5 \\
6\end{array}$ & $\begin{array}{l}\text { Anterior } \\
\text { Anterior } \\
\text { Anterior } \\
\text { Anterior } \\
\text { Anterior } \\
\text { Anterior }\end{array}$ & $\begin{array}{l}\text { Atrial fibrillation } \\
\text { Atrial fibrillation } \\
\text { Anterior } \\
\text { Atrial fibrillation } \\
\text { Atrial fibrillation } \\
\text { Atrial fibrillation }\end{array}$ & $\begin{array}{l}1 \cdot 0 \\
1 \cdot 0 \\
1 \cdot 4 \\
1 \cdot 3 \\
1 \cdot 3 \\
1 \cdot 9\end{array}$ & $\begin{array}{l}\text { Aortic and mitral valve replacement } \\
\text { Aortic and mitral valve replacement } \\
\text { Mitral valvotomy } \\
\text { Aortic and mitral valve replacement } \\
\text { Aortic and mitral valve replacement } \\
\text { Aortic and mitral valve replacement }\end{array}$ \\
\hline $\begin{array}{r}7 \\
8 \\
9 \\
10 \\
11 \\
12\end{array}$ & $\begin{array}{l}\text { Biphasic } \\
\text { Biphasic } \\
\text { Biphasic } \\
\text { Biphasic } \\
\text { Biphasic } \\
\text { Biphasic }\end{array}$ & $\begin{array}{l}\text { Anterior } \\
\text { Atrial fibrillation } \\
\text { Atrial fibrillation } \\
\text { Atrial fibrillation } \\
\text { Atrial fibrillation } \\
\text { Anterior }\end{array}$ & $\begin{array}{l}1 \cdot 3 \\
1.4 \\
0 \cdot 7 \\
1 \cdot 3 \\
\frac{1.9}{1 \cdot 9}\end{array}$ & $\begin{array}{l}\text { Aortic and mitral valve replacement } \\
\text { None } \\
\text { Mitral valve replacement } \\
\text { Aortic and mitral valve replacement } \\
\text { Aortic and mitral valve replacement } \\
\text { None }\end{array}$ \\
\hline $\begin{array}{l}13 \\
14 \\
15 \\
16 \\
17 \\
18\end{array}$ & $\begin{array}{l}\text { Posterior } \\
\text { Posterior } \\
\text { Posterior } \\
\text { Posterior } \\
\text { Posterior } \\
\text { Posterior }\end{array}$ & $\begin{array}{l}\text { Anterior } \\
\text { Atrial fibrillation } \\
\text { Anterior } \\
\text { Anterior } \\
\text { Anterior } \\
\text { Anterior }\end{array}$ & $\begin{array}{l}\frac{-}{2 \cdot 9} \\
\frac{3 \cdot 4}{1 \cdot 6}\end{array}$ & $\begin{array}{l}\text { Aortic and mitral valve replacement } \\
\text { Aortic and mitral valve replacement } \\
\text { None } \\
\text { Aortic valve replacement } \\
\text { None } \\
\text { Aortic and mitral valve replacement }\end{array}$ \\
\hline
\end{tabular}

^Mitral stenosis confirmed at operation.

†Mitral stenosis confirmed at necropsy (postoperative death). 


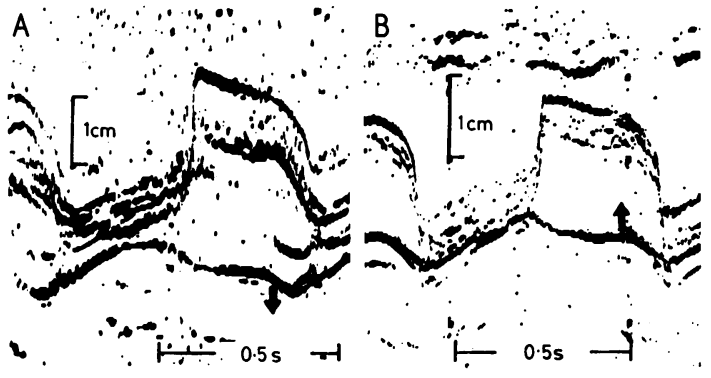

Fig. 5 Mitral echocardiogram from 2 patients with aortic stenosis. Patient $A$ had aortic stenosis only and patient $B$ had aortic and mitral stenosis. Posterior mitral valve leaflet movement with atrial systole is normal in $A$ and anterior in $B$ (arrows), indicating the coexistence of mitral stenosis in the latter.

\section{Discussion}

In the normal echocardiogram, the posterior mitral valve leaflet moves in the opposite direction to the anterior leaflet throughout diastole (Tsakiris et al., 1975). In severe mitral stenosis independent leaflet movement is lost and both valve leaflets move anteriorly with the mitral ring (Zaky et al., 1968). One might expect that with less severe mitral stenosis varying degrees of independence of movement are possible and this is confirmed by our study. The classical anterior movement was seen in only 60 per cent of the patients with isolated mitral stenosis. Another 23 per cent showed biphasic initial movement. In the remaining 17 per cent of patients initial posterior mitral valve leaflet movement was posterior. Though the patients with the mildest mitral stenosis were in this group, 2 patients had a mitral valve area below $1.3 \mathrm{~cm}^{2}$ and 5 required mitral valvotomy (Table 1). It has been suggested that such patients may have the cuspal rather than the commissural form of mitral stenosis (Ticzon et al., 1975). Nevertheless, the mitral echocardiograms of these patients were abnormal in that during atrial systole late diastolic movement of the posterior mitral valve leaflet was anterior. Presumably some commissural fusion is invariably present even in mild mitral stenosis, and this is revealed by atrial contraction at end-diastole when mitral ring movement is minimal. Since late diastolic anterior movement of the posterior mitral valve leaflet is never seen in left ventricular discompliance this is a more sensitive echocardiographic criterion for mitral stenosis than the classical early diastolic anterior movement. Unfortunately it is not available in patients with atrial fibrillation but this arrhythmia is uncommon among patients with pseudomitral stenosis.
A sweep recording from the mitral ring to the level of the chordae is necessary in order to record the most independent movement of the posterior mitral valve leaflet. Unless this is done, important information about commissural or cuspal involvement may be missed. Surgical estimation of leaflet fusion is difficult except in patients undergoing open heart surgery, but, from a review of the surgical findings in our patients, greater mobility of the valve leaflets was found in patients with biphasic or posterior movement of the posterior mitral valve leaflet than in those with anterior movement.

Echocardiographic diagnosis of mitrai stenosis in the presence of aortic stenosis is particularly important since the mitral diastolic murmur is often difficult to detect in these patients (Terzaki et al., 1970). Even at cardiac catheterisation mitral stenosis may be missed. On the echocardiogram a reduced E-F slope of the anterior mitral leaflet and posterior movement of the posterior mitral valve leaflet might be dismissed as pseudomitral stenosis. Yet 6 of 18 patients with aortic stenosis and genuine mitral stenosis showed this combination. Mitral stenosis might have been missed on the echocardiogram were it not for the fact that 5 of these patients were in sinus rhythm and late diastolic posterior mitral valve leaflet movement was anterior with atrial systole (Fig. 5).

\section{References}

Brooksby, I. A. B., Swanton, R. H., Jenkins, B. S., and WebbPeploe, M. M. (1974). Long sheath technique for introduction of catheter tip manometer or endomyocardial bioptome into left or right heart. British Heart fournal, 36, 908-912.

Duchak, J. M., Chang, S., and Feigenbaum, H. (1972). The posterior mitral valve echo and the echocardiographic diagnosis of mitral stenosis. American fournal of Cardiology, 29, 628-632.

Flaherty, J. T., Livengood, S., and Fortiun, N. J. (1975). Atypical posterior leaflet motion in echocardiogram in mitral stenosis. American fournal of Cardiology, 35, 675-678.

Goodman, D. J., Harrison, D. C., and Popp, R. L. (1974). Echocardiographic features of primary pulmonary hypertension. American fournal of Cardiology, 33, 438-443.

Gorlin, R., and Gorlin, S. G. (1951). Hydraulic formula for circulation of area of the stenotic mitral valve, other cardiac values and central circulatory shunts. American Heart Fournal, 41, 1-29

Levisman, J. A., Abassi, A. S., and Pearce, M. L. (1975). Posterior mitral leaflet motion in mitral stenosis. Circulation, 51, 511-514.

Popp, R. L. (1976). Echocardiographic assessment of cardiac disease. Circulation, 54, 538-552.

Quinones, M. A., Gaasch, W. H., Waisser, E., and Alexander, J. K. (1974). Reduction in the rate of diastolic descent of the mitral valve echogram in patients with altered left ventricular diastolic pressure-volume relations. Circulation, 49, 246-254.

Shah, P. M., Gramiak, R., and Kramer, D. H. (1969). Ultrasound localization of left ventricular outflow obstruction in 
hypertrophic obstructive cardiomyopathy. Circulation, 40, 3-11.

Stewart, S., Mason, D., and Braunwald, E. (1968). Impaired rate of left ventricular filling in idiopathic hypertrophic subaortic stenosis and valvular aortic stenosis. Circulation, 37, 8-14.

Terzaki, A. K., Cokkinos, D. V., Leachman, R. D., Meade, J. B., Hallman, G. L., and Cooley, D. A. (1970). Combined mitral and aortic valve disease. American fournal of Cardiology, 25, 588-601.

Ticzon, A. R., Damato, A. N., Caracta, A. R., Lau, S. H., and Gross, L. (1975). Echocardiographic manifestation of 'false' mitral stenosis that was. Annals of Internal Medicine, 83, 503-505.
Tsakiris, A. G., Gordon, D. A., Mathieu, Y., and Lipton, I. (1975). Motion of both mitral valve leaflets. A cineroentgenographic study in intact dogs. Fournal of Applied Physiology, 39, 359-366.

Zaky, A., Nasser, W. K., and Feigenbaum, H. (1968). Study of mitral valve action recorded by reflected ultrasound and its application in the diagnosis of mitral stenosis. Circulation, 37, 789-799.

Requests for reprints to Dr M. F. Shiu, The Cardiac Department, St Thomas' Hospital, London SE1 7EH. 